ÁREA ABIERTA. Vol. 14. № 2. Julio 2014

http://dx.doi.org/10.5209/rev_ARAB.2014.v35.n2.45755

"DR. LECTER Y MR. DEXTER MORGAN: MUTACIONES

DEL HÉROE POSTCLÁSICO EN LA FICCIÓN TELEVISIVA"

AUTORA: Raquel CRISÓSTOMO GÁLVEZ

Universitat Internacional de Catalunya, España

\title{
Dr. Lecter y Mr. Dexter Morgan: mutaciones del héroe postclásico en la ficción televisiva
}

Dr. Lecter and Mr. Dexter Morgan: mutations of the postclassic hero in television fiction 


\section{RESUMEN:}

Este artículo pretende estudiar el héroe contemporáneo y sus transformaciones en la ficción serial televisiva, llevada en los últimos tiempos al extremo en la figura protagónica del serial killer en la ya finalizada Dexter (Showtime, 2006-2013) y en Hannibal (NBC, desde 2013). Ambas ficciones son dos ejemplos altamente relevantes para la reelaboración del héroe, a la luz de la historia arquetípica que yace en la esencia de ambas: El extraño caso del doctor Jekyll y el señor Hyde de Robert Louis Stevenson y el concepto de doppelgänger que hayamos en ella. Desde una metodología cualitativa, en este estudio abordaremos en primer lugar algunas cuestiones previas sobre la transformación del héroe clásico en la serialidad contemporánea, en su paso del héroe clásico al héroe postclásico; para pasar a centrarnos en la figura del doble que ya abordaba Stevenson en su obra; y así pasar a analizar desde este punto de vista las series de Showtime y NBC en cuanto a la mutación del arquetipo heroico en su figura contemporánea.

\section{Palabras clave:}

Héroe, serial killer, Hannibal, Dexter, Lecter, series de televisión.

\section{ABSTRACT:}

This paper studies the contemporary hero and their transformations in the television serial fiction, led in recent times to the serial killer protagonist figure in the already completed Dexter (Showtime, 2006-2013) and Hannibal (NBC, from 2013). Both fictions are two highly relevant examples for the reprocessing of the hero, in the light of the archetypal story that lies at the core of both: The Strange Case of Dr. Jekyll and Mr. Hyde by Robert Louis Stevenson and its main concept of "doppelganger". From a qualitative methodology, this study first address some preliminary questions about the transformation of the classical hero in contemporary seriality, in its passage from classical to post-classical hero to move to focus on the figure of Stevenson twice already addressed in his work, and so proceed to analyze from this point of view the NBC and Showtime series about heroic archetype mutation in its contemporary figure.

\section{Key words:}

Hero, serial killer, Hannibal, Dexter, Lecter, television series. 


\section{La transformación del héroe clásico en la serialidad contemporánea: cuestiones previas}

En las series de la tercera edad de oro televisiva se aprecia una mutación en el planteamiento heroico: el héroe clásico, para quien el mundo se dividía entre el bien y el $\mathrm{mal}^{1}$, se ha despojado de sus vestiduras y progresivamente adquiere características alejadas de los estándares tradicionales narrativos, llevándolo incluso a la inversión de esta característica esencia heroica: "aquellos héroes de la tradición clásica [...] resultan cada día más ajenos a la ficción postclásica y a unos espectadores que todo lo someten a un estado de sospecha permanente"2. El héroe que antes estaba caracterizado por una profusión de propiedades positivas, cada vez más se ve abordado por una creciente indefinición y se diluye su definición convencional, dejando paso al héroe de la ficción postclásica ${ }^{3}$. El héroe postclásico puede asumir tareas características del clásico, pero el desafío, la repercusión y la prioridad que estas representan ahora respecto a las metas del personaje son algo de carácter secundario": "el papel principal lo ocupa el desafío interior, las dudas que surgen en su naturaleza [...] atrapado entre sus deseos y sus obligaciones"5. Ya no es aquel héroe solar tipificado por Joseph Campbell ${ }^{6}$ exento de dudas y de conflictos morales, con principios sólidos inquebrantables y con la misión de "proteger y servir"7. El héroe ha caído en un gris moral producto de un estado de crisis, de esa fractura identitaria, del sol negro -como el eclipse del opening crepuscular de Heroes $^{8}$ - que tiñe la mentalidad norteamericana a partir del 11-S ${ }^{9}$.

Los personajes seriales que inauguran esta etapa no tan sólo ya han dejado de ser héroes típicos (Tony Soprano en The Sopranos o Walter White en Breaking Bad) sino que progresivamente encontramos una preponderancia de la figura del asesino en serie en un rol heroico, cuando hasta hace poco los asesinos de las series tenían tan sólo pequeñas participaciones como en Whitechapel (ITV, desde 2009), o en múltiples roles secundarios como en Wallander (BBC, desde 2008) ${ }^{10}$. "El espectador ya no considera la figura del héroe convincente [...] cree fielmente en el personaje malvado [...] el mal por el mal, la

\footnotetext{
${ }^{1}$ CUADRADO ALVARADO, Alfonso. "Ulises y el héroe terrorista: mito y modernidad en la serie Homeland", Área Abierta, 2013, nº, pp. 27-42.

${ }^{2}$ CANO-GÓMEZ, A. Pablo. "El héroe de la ficción postclásica. Interpretación de la teoría del postclasicismo fílmico en la serie de televisión Hijos de la Anarquía", Palabra Clave, vol. XV, n³, diciembre 2012, p. 434.

${ }^{3}$ CANO-GÓMEZ, A. Pablo. Op.cit., p. 435.

${ }^{4}$ GONZÁleZ REQUENA, Jesús. Clásico Manierista, Postclásico: los modos del relato en el cine de Hollywood, Castilla Ediciones, Valladolid, 2006, p. 253.

${ }^{5}$ CANO-GÓMEZ, A. Pablo. Op. cit., p. 453.

${ }^{6}$ CAMPBELL, Joseph. El Héroe de las mil caras: psicoanálisis del mito, Fondo de Cultura Económica, México D.F, 1959, p. 241.

${ }^{7}$ SÁNCHEZ ESCALONILLA, Antonio. Guión de aventura y forja del héroe, Ariel, Barcelona, 2002, pp. 256.

${ }^{8}$ GÓMEZ, Francisco y BORT, Iván. "Del cine a la televisión: de 24 fotogramas por segundo a 24 episodios por temporada", Enl@ce, Revista Venezolana de Información, Tecnología y Conocimiento, vol, VI, n¹, enero- abril 2009, pp. 25-41.

9 PINTOR, Iván. "Melancolía y sacrificio en la ciencia ficción contemporánea", Formats: revista de comunicación audiovisual, n5, 2009, p. 2.

${ }^{10}$ GARCíA FANLO, Luis. "Análisis sociológico de la serie de televisión Dexter", La mirada de Telemo, nº, abril 2011.
} 
psicopatía"11. Jesús González Requena suscribe esta idea afirmando que en la época actual sólo se cree en los psicópatas porque actualmente ya no se contempla la posibilidad de hacer el bien ${ }^{12}$.

Con la aparición de Dexter Morgan en pantalla (Dexter, Showtime, 2006-2013), se formaliza la tendencia del planteamiento del asesino en serie como héroe, y sirve como detonante al surgimiento de varios protagonistas psicópatas que podemos ver recientemente en la serialidad contemporánea, como es el caso, entre otros, de "Bloody Face" en American Horror Story: Asylum (FX, 2012); Joe Carrol, el asesino en serie con una cohorte de acólitos en The Following (FOX, 2013-); el caso de Cult (CW, 2013); y el joven Norman Bates de Bates Motel (A\&E, 2013-). El serial killer protagonista está muy presente entre los protagonistas de la serialidad reciente ${ }^{13}$ y de hecho "se ha convertido en un producto rentable y en boga para la industria del entretenimiento [...] Los serial killers parecen haberse emancipado para formar su propia y fascinante cofradía" ${ }^{14}$. El referente común de todos estos personajes se encuentra en la obra de Robert Lovis Stevenson, El extraño caso del doctor Jekyll y el señor Hyde (1886), que plantea un personaje en el que pugna la dualidad entre el bien y el mal, mientras intenta vivir en sociedad pasando desapercibido ${ }^{15}$.

El propósito de este artículo es constatar la mutación de la figura heroica en la serialidad contemporánea hasta extremos como el del serial killer, a través de la última serie que ha abordado este personaje, Hannibal (NBC, 2013-), poniéndola en común con Dexter (Showtime, 2006-2013), por representar un importante punto de inflexión en el planteamiento de la figura del asesino en serie como héroe de forma sostenida, estableciendo lazos de empatía con el espectador moderno. Ambas lo hacen, ya sea durante ocho años como es el caso de Dexter, "el asesino en serie favorito de América" ${ }^{16}$; o permaneciendo en el imaginario popular desde $1991{ }^{17}$ y renovándose en el siglo XXI.

Por lo que respecta a la metodología empleada, desde una perspectiva cualitativa se hará un análisis textual de Hannibal como estudio de caso, en concreto de los personajes del doctor Hannibal Lecter y Will Graham, en contraste con el precedente inmediato de Dexter Morgan ${ }^{18}$, teniendo en cuenta el arquetipo cultural establecido por la obra de

\footnotetext{
${ }^{11}$ SÁNCHEZ CASARRUBIOS, Minerva. "Narración y sociedad: el villano en el cine contemporáneo (2000-2010)", Aequitas, vol. 2, 2012, pp. 189-224.

12 GONZÁleZ REQUENA, Jesús. Clásico Manierista, Postclásico: los modos del relato en el cine de Hollywood, Castilla Ediciones, Valladolid, 2006, pp 584.

13 HILL, Shona. y SMITH, Shilinka. "Fearful Irony: The Case of Being Dexter(ous)", en FRANKLIN, Leanne y RICHARDSON, Ravenel, (eds.). The Many Forms of Fear, Horror and Terror, Inter-Disciplinary Press, Oxford, 2009, PP. 93-102.

${ }^{14}$ CAPPELLO, Giancarlo. "El héroe como demonio. A propósito de los asesinos en serie de la ficción televisiva", La mirada de Telemo, $\mathrm{n}^{\circ}$ 6, abril 2011.

15 HASSAN, Rodha. "A Psychoanalytic analysis of the Gothic 'double'in the works of Edgar Allen Poe, Robert Lovis Stevenson and Oscar Wilde, 2013, tesis doctoral.

16 COUSELO, Felipe. "Dexter', el "serial killer" favorito de América", Libertad Digital, 2011. [http://www.libertaddigital.com/el-candelabro/201 1-10-07/dexter-el-serial-killer-favorito-de-america-

1276437492/] [consultado el 18 de marzo de 2014].

${ }^{17}$ Año de estreno de The Silence of the Lambs.

${ }^{18}$ Dexter ya ha finalizado y Hannibal va por su segunda temporada en 2014.
} 
Stevenson. La muestra se basa en las ocho temporadas de Dexter, estrenada por Showtime en 2006 y finalizada en 2013; y la primera de Hannibal, desarrollada por Bryan Fuller para NBC, con una primera temporada en 2013 y una segunda en curso en la primavera de 2014. Para el análisis de los personajes se ha tenido en cuenta bibliografía especializada.

\section{La fragmentación dual de la psique del héroe: Dexter y el pasajero oscuro}

El extraño caso del doctor Jekyll y el señor Hyde constituyó "una elaboración urbana, reflexiva, filosófica y moralista del proceso transformista que conduce del hombre a la bestia o viceversa ${ }^{19}$, y de ella resulta una concepción particularmente moderna, de una contemporaneidad asombrosa, que recoge la lucha interna a través del binomio doctor Jekyll-Mr. Hyde, por lo que se ha convertido en referente de varios héroes seriales contemporáneos. Esta obra aborda el mal que habita en cada uno en mayor o menor medida, el otro que yace en el ser propio, "esas dos regiones del bien y del mal que dividen y componen nuestra doble naturaleza" ${ }^{20}$, y que Carl Jung denomina la Sombra ${ }^{2 l}$ y lo que décadas después Dexter Morgan llamará el pasajero oscuro ${ }^{22}$. Esta fragmentación nace de la idea del doppelgänger: la novela de Stevenson es la encarnación del primer asesino en serie ficcional ${ }^{23}$ y "constituye la formulación más famosa del mito del doble"24. Este término alemán proviene de la conjugación de doppel (que significa "doble"), y gänger ("andante"), y se utiliza en referencia a "el que camina al lado"25. La denominación fue acuñada por Jean Paul en su novela Siebenkäs (1976) ${ }^{26}$ y revela "que en lo homogéneo se oculta lo heterogéneo, y acabaría por aterrizar en el campo de la psiquiatría en forma de divided self" 27 . El Romanticismo se interesó especialmente por esta desposesión del yo como materialización del lado oscuro del ser humano y se convertiría en una figura recurrente en diversos autores de la época (Henry James, Oscar Wilde, o E.T.A. Hoffman). Pócimas aparte, la innovación que Stevenson aporta al concepto de la duplicidad -reflejado previamente en obras como en Los elixires del diablo de Hoffmann (1815) o en El retrato de Dorian Grey de Wilde (1890)-, es el hecho de que ambas personalidades conviven en un mismo sujeto, sin desdoblamiento corporal, sino con una manifestación de personalidad alternante ${ }^{28}$, un hecho que sucede por primera vez en la serie televisiva de manera protagónica en la figura del asesino en serie en Dexter y

\footnotetext{
${ }^{19}$ GUBERN, Román. Máscaras de la ficción, Anagrama, Barcelona, 2002, p. 244.

${ }^{20}$ GUBERN, Román. Op. Cit., p. 251.

${ }^{21}$ ZWEIG, Connie y ABRAMS, Jeremiah (coords.). Encuentro con la sombra: el poder del lado oscuro de la naturaleza humana, Kairós, Barcelona, 1993, pp.470.

${ }^{22}$ MORELLI, Maria del Rosario (2013). "Análisis de la serie "Dexter": una aproximación a su relato en la cultura de la convergencia", La Trama de la Comunicación, 17, 151-161.

${ }^{23}$ CAPPELLO, Giancarlo. Op. cit.

${ }^{24}$ GUBERN, Roman. Op. cit., p. 252.

${ }^{25}$ ZIOLKOWSKI, Theodore. Imágenes desencantadas (una iconología literaria), Taurus, Madrid, 1980, pp. 230.

26 WEBBER, Andrew J. The Doppelgänger: Double Visions in German Literature: Double Visions in German Literature, Oxford University Press, 1996, p. 56.

${ }^{27}$ GUBERN, Roman. Op. cit., p. 13.

${ }^{28}$ GUBERN, Roman. Op. cit., p. 244.
} 
después en Hannibal, todos ellos serial killers porque el doppelgänger ha sido tradicionalmente maligno, una figura asociada a lo demoníaco ${ }^{29}$, así como Jekyll dice que Hyde era "su demonio", "un espíritu del infierno"30.

Dexter Morgan es en lo profesional un forense especializado en análisis de salpicaduras de sangre en el Departamento de Policía de Miami; y en lo personal, un buen padre y un hermano confidente. Pero Dexter Morgan es también un psicópata, un asesino en serie que en su tiempo libre busca a criminales no atrapados (o castigados) por el sistema para saciar el hambre de su pasajero oscuro. "Dexter [...] parte de una idea de tensión argumental (dos en el cuerpo de uno) para ir más allá de donde han llegado las ficciones con serial killers como protagonistas [...] Desde el punto de vista de las tradiciones narrativas, esa vuelta de tuerca [...] constituye la aportación principal de Dexter"31. Es un moderno Doctor Jekyll "que se asoma a la pequeña pantalla mediante una contradicción a priori imposible de resolver: un asesino en serie que además es policía forense" ${ }^{132}$. Durante el día Dexter persigue a los bad guys en pasiva (desde una mesa analiza salpicaduras que explican cómo ocurrió el crimen) y durante la noche lo hace de manera activa, atrapando a aquellos delincuentes que los poderes fácticos no han podido atrapar, según sus propias reglas (y su propio ritual). En Dexter la convivencia entre las dos identidades se desarrolla en un mismo ente, como ocurría en la obra de Stevenson, pero se diferencia en que en este caso no es necesaria pócima alguna que alterne la sucesión de las personalidades, sino que ambas conviven de forma simultánea, en simbiosis.

Dexter es consciente en todo momento de su pasajero oscuro, es más, su yo tranquilo y diurno prepara el camino para atrapar a los criminales que su yo sanguinario (y nocturno) exige. La dualidad en la figura del héroe no es un concepto nuevo: siempre han convivido los así llamados oficial y outlaw hero ${ }^{33}$, pero tradicionalmente lo hacían desdoblados en dos personajes; y si las dos caras convivían en un mismo personaje, en ningún caso se llegaba al extremo de tratarse de un psicópata asesino, sino, en todo caso, alguien que encarnaba las medidas tomadas al margen de la ley pero que, de cualquier modo, eran con toda claridad moralmente apropiadas, como por ejemplo ocurría en el personaje clásico de Robin Hood. Dexter captura esa tradición llevada al límite, ya que como premisa "sólo asesina a su vez a otros asesinos [...] además la acción transcurre en el estado de Florida donde sigue vigente la pena de muerte, así que de cara al espectador los asesinatos y torturas que realiza quedan eximidos de culpa" ${ }^{34}$. Dexter se rige por las reglas que su padre adoptivo Harry Morgan le marcó, lo que él llama "el código de Harry": unas normas que le aportan un intento de perspectiva ética a sus actos, así como el

\footnotetext{
29 ŽIVKOVIĆ, Milica. The Double as the" Unseen" of Culture: Toward a Definition of Doppelgänger. Facta Universitatis-Linguistics and Literature, 2000, nII, p. 125.

${ }^{30}$ STEVENSON, Robert L. El extraño caso del doctor Jekyll y Mr. Hyde, Valdemar, Madrid, 2006, p. 60.

${ }^{31}$ CARRIÓN, Jorge. Teleshakespeare, Errata Naturae, Madrid, 2012, p. 99.

32 MENÉNDEZ, Maria Isabel. "Jekyll \& Hyde en la ficción seriada norteamericana: el caso de Dexter", Revista F@ro, nำ15, 2012.

${ }^{33}$ TOUS, Anna. Mites en sèrie, Trípodos, Barcelona, 2013, pp 190.

34 HERNÁNDEZ-SANTAOLALLA, Víctor. "La amenaza de los otros: la configuración del enemigo de las series de televisión a través de la teoría de la propaganda", Previously on, nº 1, noviembre 2011, pp: 755-768.
} 
modus operandi necesario para poner en práctica su particular justicia. La supervivencia ${ }^{35}$ y la convivencia de las dos partes de Dexter sólo es posible porque este actúa bajo el amparo de la coraza ética que le proporciona el código de Harry; del mismo modo, la identificación con el espectador y la empatía que provoca en él durante ocho temporadas sólo es factible bajo ese foco de pretensiones morales: "el llamado 'código de Harry' actúa como el eje que entrelaza las dos vidas escindidas del forense y del psicópata" ${ }^{36}$. Dexter es policía y víctima a la vez, ya que su pasajero oscuro le vino dado ("I'm a survivor")"37; además vigila y acaba con los individuos que amenazan a la sociedad, y en última instancia, al espectador. "Henry Jekyll and Dexter Morgan are characters who embrace two different lives under two different identities. They both serve good and evil [...] Dexter is a serial killer who struggles to be perceived "normal" by his society" 38 . Dexter es "un héroe contemporáneo porque sus deficiencias como tal son evidentes para la audiencia, pero ello permite, precisamente, la identificación. Y también es posmoderno en el sentido de lograr esa identificación mediante la transgresión de los límites entre el bien y el mal"39.

En cada temporada de Dexter se habla de la dualidad que yace en su ser, de las dos personalidades que lo habitan en contraposición al villano, a otro asesino en serie. Las condiciones se igualan, pero el villano de cada temporada se sitúa como antagonista de Dexter, como sucede por ejemplo con su hermano Brian/Rudy ${ }^{40}$ en la primera temporada, o con su mentor Trinity en la cuarta ${ }^{41}$. Estos villanos aportan una visión poliédrica al prisma que es Dexter, ya que, a pesar de que todos ellos comparten condición con el héroe, lo complementan y explican una parte de é ${ }^{42}$. Todos ellos enfrentan al protagonista con la imagen de Dorian Grey en el espejo y le devuelven un reflejo que no le gusta, y por ese motivo todos estos personajes mueren a manos de Dexter. Estos alter egos son tan sólo una constatación de que la única dualidad que puede sobrevivir es la del héroe. Son el reflejo de lo que Dexter se habría convertido si la doctora Evelyn Vogel no hubiera instado a Harry a crear el código (si Jeckyll no hubiera puesto coto a Hyde ${ }^{43}$ ): es el monstruo per se, sin dualidades ni espacio para el bien, por lo que ya no sería posible la condición heroica de Dexter, que a medida que progresa la serie deja más espacio a sentimientos positivos,

\footnotetext{
35 "Harry was a great cop here in Miami. He taught me how to think like one; he taught me how to cover my tracks. I'm a very neat monster", temporada 1, Piloto. Traducción propia: "Harry era un gran poli en Miami. Él me enseñó como pensar como uno; me enseñó como cobrir mis huellas. Soy un monstruo muy pulido".

${ }^{36}$ CARRIÓN, Jorge. Op. cit., p. 100.

${ }^{37}$ A beautiful day, temporada 8, episodio 1.

${ }^{38}$ Traducción propia: "Henry Jekyll y Dexter Morgan son personajes que abarcan dos vidas diferentes bajo dos identidades distintas. Ambos sirven al bien y al mal [...] Dexter es un asesino en serie que lucha por ser percibido como alguien normal socialmente". KARAMEMIS, Nadide. The representation of self in darkly dreaming Dexter and The Strange Case of Dr. Jekyll and Mr. Hyde, Fatih University, 2012.

${ }^{39}$ MENÉNDEZ, Maria Isabel. Op. cit.

40 "I've lived in darkness a long time. Over the years, my eyes adjusted until the dark became my world and I could see. But then Rudy turned on the light. He flooded my memory and now I'm blind". Born free, temporada 1, episodio 12. Traducción propia: "He vivido en la oscuridad durante mucho tiempo. Durante los años mis ojos se acostumbraron hasta que la oscuridad se convirtió en mi mundo y podía ver en ella. Pero entonces Rudy encendió la luz. El inundó mi memoria y ahora estoy ciego".

41 "Trinity is a husband... a father. He's... like me", Dirty Harry, Temporada 4, episodio 5. Traducción propia: "Trinity es un marido...un padre. Él es...como yo".

${ }^{42}$ CARRIÓN, Jorge. Op. cit., p. 102.

${ }^{43}$ ROTH, Corinna. Analysis of the Double in Stevenson's "The Strange Case of Dr. Jekyll and Mr. Hyde". GRIN Verlag, 2013.
} 
como su relación consolidada con Rita, el amor por su hijo Harrison o el enamoramiento de Hannah. Recordemos que por definición la principal característica de la psicopatía es la incapacidad empática, es decir, la imposibilidad de poder aportar una respuesta emocional o de sentir remordimiento, y por ello los psicópatas se caracterizan por interactuar con las demás personas como si fuesen un objeto: la ausencia de remordimientos radica en la cosificación que hace el psicópata del otro ${ }^{44}$. Pero como le ocurre a Jekyll, Dexter Morgan lucha contra esa ausencia o dificultad de empatía ${ }^{45}$ : en la primera temporada su voz en off habla de la máscara de sentimientos que debe usar ${ }^{46}$, pero el personaje lucha contra ello a través de las tribulaciones vitales por las que tendrá que pasar $^{47}$ (el asesinato de Rita, adoptar el papel de buen padre con Harrison), hasta finalmente resolver, en la octava temporada, que sí posee sentimientos y es capaz de amar: "El Oscuro Pasajero y la lucha que Dexter entabla con él es, sin dudas, una de las razones por las cuales el espectador siente simpatía con el personaje [...] algo similar ocurre con la novela El extraño caso del doctor Jekyll y el señor Hyde de R. L. Stevenson, ya que todos simpatizamos con el atormentado Doctor Jekyll y su lucha por anular a su otro Yo"48. Pero la coartada moral de Dexter y lo que permite que el espectador siga sus actividades, es que siempre se enfrenta a un villano mayor que él. Dexter es un Jekyll moderno ${ }^{49}$ que lucha contra villanos y afronta a su pasajero oscuro, pero que se diferencia del protagonista de Stevenson en que "while Jekyll only harms his society with his second identity Mr. Hyde, Dexter's second identity, the Dark Passenger, does a favor to his society by killing only criminals" ${ }^{50}$. Dexter actúa como héroe y está de parte del espectador ya que es la recuperación actualizada de la figura del vigilante, tan arraigada en el imaginario americano ${ }^{51}$, aunque de un modo provocador, ya sea como planteamiento de la ficción o en la propia actitud del personaje, tal como puede percibirse en su opening,

\footnotetext{
${ }^{44}$ MORANA, Hilda C.P., STONE, Michael H. y ABDALLA-FILHO, Elias. "Personality disorders, psychopathy, and serial killers Transtornos de personalidade, psicopatia e serial killers", Rev Bras Psiquiatr, n²8, supl II, 2006, pp. S74-S79.

45 "If I had a heart, it would be breaking right now", Popping cherry, Temporada 1, episodio 3. Traducción propia: "Si tuviera un corazón se me estaría rompiendo ahora mismo".

46 "I love Halloween. The one time of year when everyone wears a mask... not just me. People think it's fun to pretend you're a monster. Me, I spend my life pretending I'm not. Brother, friend, boyfriend - All part of my costume collection. Some people might call me a fraud. Let's see if it will fit. I prefer to think of myself as a master of disguise", Let's give the boy a hand, temporada 1, episodio 4. Traducción propia: "Me encanta Halloween. El único momento del año en que todo el mundo lleva una máscara... no tan solo yo. A la gente le parece divertido fingir ser un monstruo. Por mi parte, me paso la vida haciendo ver que no lo soy. Hermano, amigo, novio - todos forman parte de mi colección de disfraces. Hay quien me llamaría un fraude. Veamos si encaja. Prefiero considerarme un maestro del disfraz".

47 "Born in blood, both of us, Harry was right. I thought I could change what I am, keep my family safe. But it doesn't matter what I do, what I choose. I'm what's wrong - This is fate. Hello, Arthur Mitchell", The Getaway, temporada 4, episodio 12. Traducción propia: "Nacidos en sangre, ambos a dos, Harry tenía razón. Creí que podría cambiar lo que soy, mantener a mi familia a salvo. Pero no importa lo que haga, lo que escoja. Yo soy lo que está mal. Es el destino. Hola, Arthur Mitchell".

48 GARCÍA FANLO, Luis. Op. cit. Se hace inevitable recordar aquí a Walter Bishop en Fringe (FOX, 2008-2013), mad doctor de buen corazón, que sabiéndose proclive a la psicopatía, ordena que le extirpen fragmentos de cerebro para evitar su destino natural, a costa de no tener acceso a determinadas partes de su yo.

49 SANTAULARIA, Isabel. "Dexter: Villain, Hero or Simply a Man? The Perpetuation of Traditional Masculinity in Dexter", Atlantis. Journal of the Spanish Association of Anglo-American Studies, vol. 32, n. 2, diciembre $2010, \mathrm{p}$. 68.

${ }^{50}$ Traducción propia: "mientras Jekyll solo daña a la sociedad con su segunda identidad Mr. Hyde, la segunda identidad de Dexter, el Pasajero Oscuro, hace un favor a la sociedad matando solamente a los criminales". KARAMEMIS, Nadide. Op. cit.

51 AMOORE, Lovise. "Vigilant Visualities: the Watchful Politics of the war on terror", Security Dialogue, $n^{\circ} 2, m^{2}$ arzo 2007, p. 140.
} 
al final del cual Dexter mira a cámara y saluda con una pequeña inclinación de cabeza para dejarle ver al espectador que es consciente de su mirada. El héroe muestra en este opening su ambivalencia, el juego entre identidades, entre la vida cotidiana aparentemente normal y la pulsión asesina que le invade, y el protagonista se exhibe ante el espectador haciéndolo partícipe de la ambigüedad de las imágenes y de la suya propia. $^{52}$ Dexter, al igual que todo asesino en serie se presenta como un ser frío y calculador, sobre todo en su primera temporada, incapaz de sentir lástima por sus víctimas y empatía con sus iguales. ${ }^{53}$ Sin embargo consigue seducir a su público a través de su calidad de víctima, de vigilante social y de buen padre y hermano, al igual que el doctor Lecter, del que hablaremos a continuación.

\section{Hannibal: la inversión del héroe dual}

La trama de Hannibal (NBC, desde 2013) se basa en la obra El Dragón Rojo de Thomas Harris, anterior a El silencio de los corderos ${ }^{54}$. La serie se centra en la relación entre el investigador especial del FBI, Will Graham, y el doctor Hannibal Lecter, psiquiatra forense. Will es un agente inactivo con escasas habilidades sociales ${ }^{55}$ que es reclamado por su superior Jack Crawford para que le ayude a resolver un difícil caso. Will malvive con un extraño don, una insólita capacidad para la imaginación ${ }^{56}$, una extraña forma de empatía que le traslada a la mente de los asesinos que persigue, hasta sus más recónditos lugares psíquicos, para reconstruir paso a paso todos sus crímenes y finalmente capturarles; pero experimenta cada vez mayores problemas para regresar de esas mentes ajenas. A esto hay que añadir las ensoñaciones que experimenta, momentos de inconsciencia cada vez más habituales, prácticamente episodios de sonambulismo que recuerdan a los momentos de alucinación en los que Dexter habla con el fantasma de Harry, momentos fronterizos del yo de ambos héroes, donde se nos descubren las bisagras, las costuras, de la dualidad que les posee ${ }^{57}$. El doctor Hannibal Lecter entra en escena cuando el FBI necesita realizar un perfil del criminal y se hace patente que la estabilidad mental de Will puede empeorar a medida que trabaja en los casos y se enfrenta a los criminales en serie. Lecter actúa en calidad de compañero y tutor mental, y mediante sus sesiones intenta ayudar a Will a no caer en el abismo de horror de las mentes de los psicópatas a los que persiguen. Pero la extraña capacidad de Will y la encefalitis cada

\footnotetext{
${ }^{52}$ BORT, Ivan. Nuevos paradigmas en los telones del relato audiovisual contemporáneo, Universitat Jaume I. 2012.

${ }^{53}$ CAPPELLO, Giancarlo. Op. cit.

${ }^{54}$ Bryan Fuller ha desarrollado la trama de la primera temporada a partir de algunos personajes de El Dragón Rojo, pues las tramas y personajes esenciales de El silencio de los corderos y Hannibal están en manos de MGM.

55 "- Crawford: Then help me find some evidence. - Graham: That may require me to be social." Apéritif, piloto. Traducción propia: - Crawford: Entonces ayúdame a encontrar evidencias. - Graham: Eso me requeriría ser social".

56 "Can I borrow your imagination?". Apéritif. Traducción propia: "¿Puedo tomar prestada tu imaginación?"

57 "You catch these killers by getting into their heads, but you also allow them into your own", Savorueux, temporada 1, episodio 12. Traducción propia: "Tú atrapas a esos asesinos metiéndote en sus cabezas, pero a la vez permites que ellos entren en la tuya".
} 
vez más aguda (que padece sin saberlo) le aíslan cada vez más, hasta finalmente trasladarlo (aparentemente) al terreno de la psicopatía al acabar la primera temporada.

De la mano de Will, el espectador se adentra en la mente del asesino y se muestran las horribles escenas mentales, que progresivamente se descubrirá que aportan tanta información sobre el asesino como de los dos protagonistas; sobre todo a medida que avance la segunda temporada en que Will convierte la presencia pesadillesca de Lecter en una figuración oscura con gran cornamenta propia del antílope amenazante que invadía su mente en la temporada anterior. En Hannibal existe una cuestión importante sobre la verosimilitud desprendida por el tejido narrativo, con importantes trampas en la forma y tiempos de la narración. La verosimilitud se resiente en la serie hasta el punto de que el espectador pronto percibe que quizás los personajes principales, de los que no cabía dudar, son responsables de actos que no se han mostrado. Esto lleva a que el espectador ponga en tela de juicio permanente la realidad presentada, al igual que ocurre con el narrador engañoso que son las voces en off de Dexter Morgan y el doctor Jekyll. Los tres personajes viven en mayor o menor medida en una realidad ambivalente y difusa donde no pueden estar seguros ni de sus actos, comprometiendo todo el sentido de su presencia en la historia. Así, es en las pesadillas de Will, en su teatro interior ${ }^{58}$ es donde asistimos a la verdadera esencia de los personajes que nos rodean, y lo hacemos desde la distorsión de una mente trastornada, desde el terreno uncanny ${ }^{59}$ del doppelgänger, que E.T.A. Hoffmann definía como la representación del sujeto en su división patológica entre realidad y fantasía, un dualismo crónico (chronischer dualismus) ${ }^{60}$. Como figura imaginada que es, el doble existe en una relación dependiente con el original (como las figuraciones creadas por Will en su cabeza dependen de él; como el pasajero oscuro de Dexter depende de él, y como en última instancia Mr. Hyde depende del Dr. Jekyll); y si su poder imaginativo radica en su inmaterialidad, el poder psicológico del doble radica en su ambigüedad, en el hecho de que puede resultar un contraste pero que se apoyan en similitudes ${ }^{61}$. El intento de establecer un marcado contraste se aprecia en que los tres personajes originales tengan profesiones reconocidamente asociadas con lo racional: Jeckyll era doctor, Dexter es forense, y el Dr. Lecter es psicólogo (así como Will es profesor).

Hannibal prescinde de la moralidad que se plantea continuamente Dexter Morgan ya desde su premisa, y potencia la estilización de la violencia. La atmósfera es inquietante y la estética posee una identidad propia y está encaminada a mostrar los hechos desde el punto de vista del villano. Desde las ropas atildadas de Lecter y los asesinatos, pasando por su gastronomía: toda la fotografía está plagada de imágenes perturbadoras realizadas con un tratamiento pictórico, plástico, de forma semejante a los primeros planos hiperrealistas que se suceden en el opening de Dexter. Sin embargo, en la ficción

\footnotetext{
${ }^{58}$ REINEL, José. "David Hume. La imposibilidad de un progreso en los sentimientos morales", Revista de Filosofía, vol. 68, 2012, pp. 115-132.

59 VARDOULAKIS, Dimitris. The return of negation: the Doppelganger in Freud's" The 'Uncanny"'. SubStance, vol. $35, n^{\circ} 2,2006$, p. 100.

${ }^{60}$ WEBBER, Andrew. Op. Cit., p. 1.

${ }^{61}$ ŽIVKOVIĆ, Milica, Op. Cit. p. 124.
} 
de Showtime los asesinatos cometidos por su protagonista son asépticas puestas en escena envueltas en plástico transparente; y por oposición, los asesinatos realizados por los criminales a los que persigue Dexter sí son detallados en el horror de las imágenes, lo que se corresponde con una absoluta limpieza literal y moral del héroe. En Hannibal, los asesinatos se muestran con todo tipo de detalle ${ }^{62}$; y por lo que respecta a los crímenes del asesino protagonista, el foco no es aséptico como ocurría en Dexter, pero sólo muestra el horror implícito, las consecuencias de la premisa: sino tan sólo serían imágenes de cocina. El espectador sólo ve dos cosas: la materia prima con la que Lecter cocina ly que en apariencia se podrían encontrar con cierta facilidad en cualquier mercado o tienda gourmet ${ }^{63}$ y los magníficos platos que prepara, con un mimo exquisito en su emplatado. El espectador en un principio sólo asiste a la preparación de la receta y a su presentación en mesa. Pero con la diferencia de que la información está en el referente, ya que la ficción se apoya en la recepción de la premisa por parte del espectador, que sabe quién es Hanníbal Lecter - personaje que popularizó Anthony Hopkins en El silencio de los corderos (1991) de Jonathan Demme- y por lo tanto sabe que Lecter es caníbal. En la serie (y en el personaje del doctor Lecter) se unen la repulsión y la sofisticación, en esa dualidad es la que navega el espectador durante la serie: existe una suerte de belleza visual en las imágenes de la serie, una artistificación que presenta tanto los asesinatos como la comida, bajo una fotografía que se asemeja en unas ocasiones a una pintura tenebrista en la que prima una paleta de colores granates y rojos donde algunos elementos acaparan la luz y el protagonismo de la escena; y en otras a un bodegón, a la naturaleza muerta (literalmente) que nos muestran las imágenes promocionales donde la comida tiene un protagonismo determinante: un tenedor de plata brillante pulida con un filo hilo de sangre; o los personajes principales sentados alrededor de una mesa con un banquete pantagruélico, situado encima de ropajes y frutas. Esta estilización del crimen, de lo morboso y de lo pesadillesco tiene mucho que ver con la percepción de Hannibal, ya que en su trastorno "él no come a su víctimas, trata de convertirlas de objetos malos y persecutorios a objetos artísticos, instructivos y buenos, por eso entiende el actuar de los otros asesinos seriales, diciendo que la clave es "transformación" ${ }^{64}$. La sofisticación de los platos (no en balde concebidos por el chef español José Andrés y diseñados en su composición en plato por la estilista Janice Poon) no es gratuita, al igual que su protagonismo en la serie, ya que cada episodio lleva el nombre de una receta (sorbet, rôti, potage...), dado que la comida en Hannibal son los actos criminales del que se nos presenta como héroe, del protagonista que seduce al espectador y a sus comensales, a pesar de su condición de asesino, exhibiéndose como perfecto anfitrión, al igual que lo hacía Dexter Morgan al finalizar el opening de su serie. De hecho, en los créditos iniciales de Hannibal podemos ver como sobre un fondo blanco fluye y se derrama un líquido rojo, con la ligereza del vino, pero que juega en su ambivalencia con lo que podría ser sangre,

${ }_{62}$ ABBOTT, Stacey. "TV Special effects", Critical Studies in Television, vol. 8, n³, otoño 2013, pp. vii-xii.
${ }^{63}$ Hasta en la segunda temporada que excepcionalmente se puede ver que se trata de una pierna humana
(Sakizuke, segunda temporada, episodio dos).
${ }^{64}$ BLANCO, Lucio. "Psicopatología en el cine: Hannibal Lecter de Thomas Harris", La psiquiatría en el siglo xxi:
realidad y compromiso, pp. 225-228.
[http://wWw.gladet.org.mx/publicaciones/Realidad\%20y\%20Compromiso.pdf\#page=225], consultado el 18/03/2014] 
hasta conformar una efigie humana que alude y referencia al Lecter encarnado por Anthony Hopkins cuando, al acabar de dibujar la mandíbula, parece conformar un bozal.

La estética de la serie es en gran parte también la responsable de que Hannibal parezca transcurrir en un mundo irreal. La sensación para el espectador es la de estar inmerso en una de las pesadillas de Will, dentro de su imaginación en la línea del relato engañoso al que nos referíamos, ya que toda la narración transcurre en espacios cerrados y sólo se nos muestran espacios abiertos relacionados con la naturaleza, con paisajes fríos que anuncian muerte por sí solos. En más de una ocasión parece que la trama se suceda entre pinturas de cámara (la consulta y el comedor del doctor Lecter y la consulta de la doctora Du Maurier) y paisajes de caza con numerosos alces y otras presas (como la cabaña de Garrett Jacob Hobbs o la casa aislada de Will). Sin embargo, la paleta de colores que circunda a los espacios asociados con Will es altamente fría (el depósito de cadáveres, su casa, las clases), a diferencia de los tonos cálidos que encuentran una base en el rojo que rodean a Hannibal (las maderas de su despacho y el ambiente acogedor de las estancias regadas con buena comida y buenos burdeos). La estética recuerda así al espectador que el héroe moribundo en realidad es Will, en contraposición a la seductora vitalidad que rezuma Lecter como héroe.

Asimismo, la estilización también tiene mucho que ver en la construcción de los personajes: el doctor Lecter de Hannibal poco tiene que ver con su referente cinematográfico interpretado por Anthony Hopkins. Éste era Hannibal el caníbal, un asesino psicópata convicto encerrado con mirada de perturbado y portador de una máscara a modo de bozal que lo animalizaba y que se convertiría en un icono referencial en la imaginería popular. El doctor Lecter de Mads Mikkelsen se caracteriza por un marcado estilo que se transmite a través de su rostro, sus maneras y el gusto por la cuisine. Su vestuario resulta elegante y roza el dandismo, cuidando con esmero su atuendo ${ }^{65}$, una diferenciación de la que también hay mucho del doctor Jeckyll y del señor Hyde en sí misma. La parte estética del Lecter de Mikkelsen configura un escaparate harto refinado que resulta seductor y que encaja con la complejidad mental del personaje: se trata de alguien preciso y sofisticado, no solo en sus gustos, sino en la complejidad mental de sus delitos. Nada hace pensar en su condición de asesino, tal como ocurre en Dexter: "His eyes are not dark or deadly and he has a rosy complexion. He is a literal picture of health, not insanity. Visually his is not a collective representation of evil and it is difficult to see anything in the image [...] that would provoke fear" ".6 . Esta tipología de malvado héroe bello se puede rastrear "en el Satanás de Milton 'de belleza decaída, de esplendor ofuscado por la melancolía y la muerte' [...] y se perfeccionaría a manos de Byron [...] La figura del demonio a partir de entonces va a estar marcada por la ambigüedad. Las

\footnotetext{
65 "He's not a tipical psycho... he's a dandy"; "He's a lover of the fine arts, a lover of food...a man of taste, a man of details... he's a perfectionist". Comentarios de Bryan Fuller y Mads Mikkelsen [http://www.youtube.com/watch? $v=\ln 6 B$ BuZb9z8], consultado el 8-8-2013] y [http://www.youtube.com/watch?v=LdnxAl1 mlFs], consultado el 9-8-2013], respectivamente.

${ }^{66}$ Traducción propia: "Su mirada no es oscura o mortífera y de hecho posee una piel sonrosada. Es literalmente la viva imagen de la salud, no de la enfermedad. Visualmente no encarna la representación del mal y es dificil ver algo en su imagen que provoque miedo". SMITH, Victoria L.. "Our Serial Killer, Our Superheroes, and Ourselves: Showtime's Dexter", Quarterly Review of Film and Video, vol. 28, n5, septiembre 2011, pp. 390-400.
} 
historias nos contarán que son violentos y amenazantes, pero a la vez que sufren y son perseguidos", ${ }^{67}$ acogiéndose al trauma que suele haber en el origen de estos asesinos heroicos, como el que tanto Hannibal ${ }^{68}$ (del modo que se narra en Hannibal Rising, la precuela cinematográfica de la saga, dirigida por Peter Webber en 2007) como Dexter sufrieron en su niñez (desvelado en "Born Free", episodio 12 de la primera temporada).

En cuanto a la parte emocional, el Lecter de Anthony Hopkins parece disfrutar con el vínculo que le une a Clarice Starling y en virtud del cual decide dejarla vivir. No obstante, aparte de este atisbo de vínculo, el personaje de Lecter no parece tener sentimientos por ningún otro personaje, correspondiéndose con el patrón clásico de un psicópata. Ahora bien: el Lecter de Mikkelsen sí tiene varias relaciones. Para empezar, aquella que le une a Will Graham, su paciente, por quién sabemos que llega a sentir incluso una cierta amistad, ya que le reconoce a la doctora Bedelia Du Maurier (Gillian Anderson) que cree haber encontrado un verdadero amigo en Will ${ }^{69}$. No es una amistad emocional o mentalmente sana, bien intencionada $u$ honesta, pero es mucho más de lo que encontramos en el protagonista de El silencio de los corderos. Además, Lecter deja traslucir que se siente responsable del personaje de Abigail Hobbs, la hija del asesino en serie Garrett Jacob Hobbs. La juventud de Abigail y las dudas que asaltan a la adolescente sobre si habrá heredado la locura de su depravado padre conforman una combinación irresistible para Lecter, que entabla relación con Abigail mediante la empatía y la comprensión, hasta formar parte activa de la vida de la joven ${ }^{70}$, acercándose a la figura paterna o del tutor. La diferencia con Dexter es que el doctor Lecter malinterpreta o no es capaz de desarrollar el concepto de amistad con normalidad debido a su condición de psicópata y manipula a Will a su conveniencia, a diferencia de Dexter, que anhela tener un compañero, un amigo, una novia; y en cuanto al amor filial,

Hannibal posee más interés por los mecanismos psicopatológicos que empiezan a despertarse en Abigail, que por la posibilidad de la idea de la paternidad, al contrario que Dexter que desarrolla amor por Harrison y empatía por Zach, su breve hijo espiritual en la octava temporada. Todos estos elementos hacen que Lecter no posea la empatía y la comprensión que sí despierta Dexter en el espectador. Y que necesite a Will, un héroe más clásico a su lado. El psicólogo aparece aquí como un individuo bipolar sometido al esquema básico de la dualidad encerrado en el arquetipo del doctor Jekyll y el señor Hyde: "Si el asesino es un monstruo, encarnación del mal absoluto [...] el policía es representado como su Némesis absoluta, es decir, un héroe, encarnación del bien absoluto, que sacrifica su propia vida privada al servicio del cuerpo policial y la sociedad, y que combina racionalidad con empatía hacia las víctimas con las que se involucra personalmente" 71 , como Will se involucra hasta la enfermedad ${ }^{72}$. Hannibal es la inversión

\footnotetext{
${ }^{67}$ CAPPELLO, Giancarlo. Op. cit.

68 BLANCO, Lucio. Op. Cit.

69 "Hannibal refers to Will Graham more as a friend than a patient", Releves, temporada 1, episodio 11. Traducción propia: "Hannibal se refiere a Will Graham más como a un amigo que como a un paciente".

70 "I'm so sorry Abigail. I'm sorry I couldn't protect you in this life", Releves. Traducción propia: "Lo siento mucho Abigail. Siento no haber podido protegerte en esta vida".

${ }^{71}$ GARCÍA FANLO, Luis. Op. cit.

72 "He said he got so close to Garrett Jacob Hobbs and what he done; he felt he was becoming him", Releves.
} 
de los roles: si en Dexter veíamos el oxímoron definitivo en cuanto a la confluencia entre policía y asesino en un solo ser, en el doctor Lecter vemos la convergencia de psicólogo y psicópata asesino que acaba con la psicología de su némesis, la figura de orden que es Will, alzándose como héroe y ratificándose en su ambigüedad. Cuanto más controlado y racional se muestra profesionalmente Lecter, más irracional es la conducta de Will, quien busca la coherencia a través del túnel del comportamiento enfermo de las mentes asesinas, terminando por desdibujar lo correcto y por perderse en un escenario mental de locura heredada. De esta forma Hannibal también canibaliza en la segunda temporada el rol de profiler $^{73}$ del FBI que Will tenía hasta entonces ${ }^{74}$.

La serie plantea dos planos de coherencia, espejos de la psique dividida de Will, como el personaje de la novela de Stevenson: un primer plano en el que los personajes actúan conforme a mapas lógicos de decisión social (de represión victoriana en el caso de Stevenson) donde sus actos son producto de una relación causa-efecto comprensible, y cuyo comportamiento se ajusta a parámetros lógico-emocionales. En este primer plano, Will intenta desarrollar sus sentimientos románticos para con la Dra. Alana Bloom y Hannibal trata sus asuntos psicológicos (y sería donde Dexter ejercería como forense); y en un segundo plano, solo sobrevive la coherencia de las perturbadas mentes de los asesinos, comprensibles mediante la empatía exacerbada de Will, al coste de traerse consigue un pasajero oscuro como el de Dexter en cada viaje, donde Mr. Hyde queda liberado ${ }^{75}$. Los detectives de los thrillers de asesinos en serie "pagan un precio muy alto por verse involucrados en el proceso de investigación"76, "ganan en experiencia y conocimiento, pero pierden su inocencia en el camino"77.

\section{Conclusiones}

Podemos concluir por tanto que el héroe postclásico ha mutado hacia su extremo bajo la alargada sombra del doppelgänger de Stevenson, poniéndose en la piel de asesinos en serie como Dexter y Hannibal, pero conservando en cualquier caso características que les convierten en héroes. A pesar de sus actos reprobables y dentro de esa dualidad

\footnotetext{
Traducción propia: "Dijo que se había acercado tanto a Garrett Jacob Hobbs y a lo que había hecho; que sentía que se estaba convirtiendo en él".

${ }^{73}$ HOLmES, Ronald y HOLMES, Stephen: Profiling violent crimes, SAGE Publications, London, 2009.

${ }^{74} \mathrm{Hannibal}$ establece un fuerte lazo intertextual con Millennium (FOX, 1996-1999), de Chris Carter, donde el ex agente del FBI Frank Black tiene la habilidad de ponerse en la piel de los asesinos en serie y ver el mundo desde su perspectiva a través de un viaje oscuro a la mente del asesino. En lo que concierne al personaje de Will Graham de Hannibal, la principal diferencia es el efecto que este viaje mental tiene para el personaje principal. En el caso de Will el viaje tiene un impacto implacable sobre su salud mental, que paulatinamente se erosiona, pasándole factura a modo de pesadillas, alucinaciones, ausencias, etc., e incluso con un solapamiento de las acciones cometidas. En cambio, Frank Black parece ser capaz de controlar los efectos de esa empatía salvaje y oscura manteniendo su cordura.

75 "Last time you send me into a darkplace, I brought something back". Apéritif. Traducción propia: "La última vez que me mandaste a un lugar oscuro, traje algo de vuelta ".

${ }^{76}$ CAPPELLO, Giancarlo. Op. cit.

77 SANTAULARIA, Isabel. El monstruo humano. Una introducción a la ficción de los asesinos en serie, Laertes, Barcelona, 2008, pp. 218.
} 
simultánea (a diferencia de lo que ocurría en la obra de Stevenson), los dos encuentran una coartada moral a sus actos.

Recogiendo los diversos aspectos que hemos tratado durante este análisis podemos observar que esa coartada se ve caracterizada por matar sólo a los que son peor que ellos, ya que ésta es la premisa de Dexter y Hannibal no ha matado todavía a quien no lo mereciera o le amenazara ante la cámara ${ }^{78}$. Asimismo es importante también la empatía, y la capacidad de mímesis social que estos personajes presentan, que esconde el monstruo y que el caballero victoriano que era el Dr. Jekyll no necesitaba por tratarse de una dualidad no simultánea. Y finalmente que ambos podrían ser pensados originariamente como víctimas, ya que la degeneración moral de sus actos originariamente es fruto de un trauma infantil, lo que intentaría excusar la psicopatía, estableciendo así lazos empáticos con el espectador, sin dejar de ser los héroes de la narración. La fragmentación psicológica, el doppelgänger por lo tanto, la crisis identitaria por lo tanto es producto de la circunstancia, como para Stevenson lo era de la encorsetada sociedad victoriana.

\footnotetext{
${ }^{78}$ En una ocasión en defensa propia al atacarle el asesino en serie Tobias y al paciente Franklin Froideveaux, que a esas alturas de la serie ya se ha hecho tan insoportable para el espectador como para Lecter ("Fromage", episodio 8).
} 


\section{BIBLIOGRAFÍA}

ABBOTT, Stacey, "TV Special effects", Critical Studies in Television, vol. 8, n³, otoño 2013, pp. vii-xii.

AMOORE, Louise. "Vigilant Visualities: the Watchful Politics of the war on terror", Security Dialogue, no 2 (2007), pp. 139-156.

BLANCO, Lucio, "Psicopatología en el cine: Hannibal Lecter de Thomas Harris", La psiquiatría en el siglo xxi: realidad y compromiso, pp. 225-228. [http://www.gladet.org.mx/publicaciones/Realidad\%20y\%20Compromiso.pdf\#page=225], consultado el 18/03/2014]

BORT, Ivan. Nuevos paradigmas en los telones del relato audiovisual contemporáneo, Universitat Jaume I, Castellón, 2012.

CANO-GÓMEZ, A. Pablo. "El héroe de la ficción postclásica. Interpretación de la teoría del postclasicismo fílmico en la serie de televisión Hijos de la Anarquía", Palabra Clave, vol. $X V, n^{\circ} 3$ (2012), pp. 432-457.

CAMPBELL, Joseph. El Héroe de las mil caras: psicoanálisis del mito, Fondo de Cultura Económica, México D.F., 1959.

CAPPELLO, Giancarlo. "El héroe como demonio. A propósito de los asesinos en serie de la ficción televisiva", La mirada de Telemo, nº (2011),

[http://revistas.pucp.edu.pe/index.php/lamiradadetelemo/article/view/3528/3408],

consultado el 11 de marzo de 2014 .

CARRIÓN, Jorge. Teleshakespeare, Errata Naturae, Madrid, 2012.

COUSELO, Felipe. "'Dexter', el "serial killer" favorito de América", Libertad Digital, 2011. [http://www.libertaddigital.com/el-candelabro/201 1-10-07/dexter-el-serial-killer-favoritode-america-1276437492/] [consultado el 18 de marzo de 2014].

CUADRADO ALVARADO, Alfonso. "Ulises y el héroe terrorista: mito y modernidad en la serie Homeland", Área Abierta, 2013, n¹, pp. 27-42.

FERNÁNDEZ, David, "Clásico Manierista, Postclásico: los modos del relato en el cine de Hollywood", Comunicación y hombre: revista interdisciplinar de ciencias de la comunicación y humanidades, n² 2, 2006, pp. 151-154.

GARCÍA FANLO, Luis. "Análisis sociológico de la serie de televisión Dexter", La mirada de Telemo, no 6 (2011),

[http://revistas.pucp.edu.pe/index.php/lamiradadetelemo/article/view/3524/3403],

consultado el 11 de marzo de 2014. 
GÓMEZ, Francisco y BORT, Iván. "Del cine a la televisión: de 24 fotogramas por segundo a 24 episodios por temporada", Enl@ce, Revista Venezolana de Información, Tecnología y Conocimiento, vol, VI, $n^{\circ} 1$ (2009), pp. 25-41.

GONZÁLEZ REQUENA, Jesús. Clásico Manierista, Postclásico: los modos del relato en el cine de Hollywood, Castilla Ediciones, Valladolid, 2006.

GUBERN, Roman. Máscaras de la ficción, Anagrama, Barcelona, 2002.

HASSAN, Rodha. "A Psychoanalytic analysis of the Gothic 'double' in the works of Edgar Allan Poe, Robert Lovis Stevenson and Oscar Wilde, 2013, tesis doctoral.

HERNÁNDEZ-SANTAOLALLA, Víctor. "La amenaza de los otros: la configuración del enemigo de las series de televisión a través de la teoría de la propaganda", Previously on, $n^{\circ} 1$ (201 1), pp: 755-768.

HILL, Shona. y SMITH, Shilinka. "Fearful Irony: The Case of Being Dexter(ous)", en FRANKLIN, Leanne y RICHARDSON, Ravenel, (eds.), The Many Forms of Fear, Horror and Terror, InterDisciplinary Press, Oxford, 2009, pp. 93-102.

HOLMES, Ronald y HOLMES, Stephen: Profiling violent crimes, SAGE Publications, London, 2009.

KARAMEMIS, Nadide. The representation of self in darkly dreaming Dexter and The Strange Case of Dr. Jekyll and Mr. Hyde, Fatih University, Estambul, 2012.

MENÉNDEZ, Maria Isabel. "Jekyll \& Hyde en la ficción seriada norteamericana: el caso de Dexter", Revista F@ro, n¹5 (2012),

[http://www.revistafaro.cl/index.php/Faro/article/view/51/38], consultado el 11 de marzo de 2014.

MORANA, Hilda C.P., STONE, Michael H. y ABDALLA-FILHO, Elias. "Personality disorders, psychopathy, and serial killers Transtornos de personalidade, psicopatia e serial killers", Rev Bras Psiquiatr, n²8, supl. II (2006), pp. S74-S79.

MORELLI, Maria del Rosario. "Análisis de la serie "Dexter": una aproximación a su relato en la cultura de la convergencia", La Trama de la Comunicación, n 17 (2013), pp. 151-161.

PINTOR, IVán. "Melancolía y sacrificio en la ciencia ficción contemporánea", Formats: revista de comunicación audiovisual, n5 (2009), p. 2.

REINEL, José, "David Hume. La imposibilidad de un progreso en los sentimientos morales", Revista de Filosofía, vol. 68, 2012, pp. 115-132. 
ROTH, Corinna. Analysis of the Double in Stevenson's "The Strange Case of Dr. Jekyll and Mr. Hyde". GRIN Verlag, 2013.

SÁNCHEZ CASARRUBIOS, Minerva. "Narración y sociedad: el villano en el cine contemporáneo (2000-2010)", Aequitas, vol. 2 (2012), pp. 189-224.

SÁNCHEZ ESCALONILLA, Antonio. Guión de aventura y forja del héroe, Ariel, Barcelona 2002.

SANTAULARIA, Isabel. El monstruo humano. Una introducción a la ficción de los asesinos en serie, Laertes, Barcelona, 2008.

SANTAULARIA, Isabel. "Dexter: Villain, Hero or Simply a Man? The Perpetuation of Traditional Masculinity in Dexter", Atlantis. Journal of the Spanish Association of Anglo-American Studies, vol. 32, n. 2 (2010), pp. 57-71.

SMITH, Victoria L. "Our Serial Killer, Our Superheroes, and Ourselves: Showtime's Dexter", Quarterly Review of Film and Video, vol. 28, n5 (2011), pp. 390-400.

STEVENSON, Robert L. El extraño caso del doctor Jekyll y Mr. Hyde, Valdemar, Madrid, 2006.

TOUS, Anna. Mites en sèrie, Trípodos, Barcelona, 2013.

VARDOULAKIS, Dimitris. The return of negation: the Doppelganger in Freud's" The'Uncanny"'. Substance, vol. 35, n², 2006, pp. 100-116.

WEBBER, Andrew J. The Doppelgänger: Double Visions in German Literature: Double Visions in German Literature, Oxford University Press, 1996.

ZIOLKOWSKI, Theodore. Imágenes desencantadas (una iconología literaria), Taurus, Madrid, 1980.

ŽIVKOVIĆ, Milica. The Double as the "Unseen" of Culture: Toward a Definition of Doppelgänger. Facta Universitatis-Linguistics and Literature, 2000, nºl, p. 121-128.

ZWEIG, Connie y ABRAMS, Jeremiah (coords.). Encuentro con la sombra: el poder del lado oscuro de la naturaleza humana, 28 de junio. 